\title{
Intense Uptake of Liposomal Curcumin by Multiple Myeloma Cell Lines: Comparison to Normal Lymphocytes, Red Blood Cells and Chronic Lymphocytic Leukemia Cells
}

\author{
GORDON T. BOLGER ${ }^{1}$, ALBERT LICOLLARI ${ }^{1}$, RICHARD BAGSHAW $^{1}$, AIMIN TAN $^{1}$, \\ RICHARD GREIL ${ }^{2}$, BRIGITTA VCELAR ${ }^{3}$, MUHAMMED MAJEED ${ }^{4}$ and PETER SORDILLO ${ }^{5}$ \\ ${ }^{1}$ Nucro-Technics, Scarborough, ON, Canada; \\ ${ }^{2}$ Third Medical Department with Hematology and Medical Oncology, Oncologic Center Salzburg Cancer Research, \\ Paracelsus Medical University, Institute, Cancer Cluster, Salzburg, Austria; \\ ${ }^{3}$ Polymun Scientific Immunbiologische Forschung GmbH, Klosterneuburg, Austria; \\ ${ }^{4}$ Sabinsa Corporation, East Windsor, NJ, U.S.A.; \\ ${ }^{5}$ SignPath Pharma Inc., New York, NY, U.S.A.
}

\begin{abstract}
Background/Aim: Curcumin is being widely investigated for its anticancer properties and several studies in the literature suggest that curcumin is distributed to a higher degree in cancer cells compared to normal cells. The goal of this study was to investigate the disposition of curcumin in the form of Lipocurc ${ }^{T M}$ in multiple myeloma (MM)-causing plasma cell lines and B-lymphocytes from healthy individuals and compare the uptake to previously published data for red blood cells (RBCs), peripheral blood mononuclear cells (PBMCs) from healthy individuals and PBMCs from patients with chronic lymphocytic leukemia (CLL-cells). Materials and Methods: Two MM-producing cell lines were studied: RPMI-8266, an IgG lambda cell line, and NCL-H929, an IgA kappa line. The distribution of liposomal curcumin and its metabolism to the major stable metabolite tetrahydrocurcumin (THC) were measured in vitro in the cell lines and B-lymphocytes. The cells were incubated in plasma protein-supplemented media with liposomal curcumin (Lipocurc ${ }^{T M}$ ) for 15 min at $37^{\circ} \mathrm{C}$ and the levels of curcumin and THC in cells and medium were determined by liquid chromatography tandem mass spectrometry. Results: Extremely intense uptake was seen in both MM lines compared to that in B-lymphocytes and
\end{abstract}

This article is freely accessible online.

Correspondence to: Peter Sordillo SignPath Pharma, Inc., 51 East 82 Street, \#1A, New York, NY 10028, U.S.A. Tel: +1 2127375706, e-mail: psordillo@signpathpharma.com or Gordon T. Bolger, Nucro-Technics, 2000 Ellesmere Road, Unit 16, Scarborough, Ontario, M1H 2W4, Canada. Tel: +1 4164386727, email: bolger@nucro-technics.com

Key Words: Curcumin, tetrahydrocurcumin, B-lymphocytes, peripheral blood mononuclear cells, distribution, metabolism. previously published data in RBCs, PBMCs and CLL cells. The levels of curcumin in RPMI-8266 and NCI-H929 cells were $14,225 \pm 847$ and $12,723 \pm 500 \mathrm{pg} / 10^{6}$ cells compared to $19 \pm 5,587 \pm 86$ and $3,122 \pm 166 \mathrm{pg} / 10^{6}$ cells in RBCs, PBMCs and CLL cells, respectively. Conversion of curcumin to THC was greatest in PBMCs, considerably less in CLL cells and minimal or absent in B-lymphocytes and MM cell lines. Conclusion: The extremely intense uptake of curcumin (as Lipocurc ${ }^{T M}$ ) in both MM lines further suggests that Lipocurc ${ }^{T M}$ should be investigated in the treatment of patients with this disease.

Curcumin (diferuloylmethane) (Figure 1) is being investigated for its anticancer properties in a number of blood-borne cancer types, most notably, chronic lymphocyte leukemia (CLL) and myeloma, with several studies indicating its potential for therapeutic benefit (1-8). The therapeutic benefits of curcumin in CLL have been extensively reviewed and a role in maintenance therapy proposed (1-3). At the cellular level, curcumin on its own has been shown to induce apoptosis of CLL B-cells with a 4-fold greater potency compared to B-cells from a healthy individual, an observation that was linked to reduction of cell levels of nuclear factor $\mathrm{kB}(\mathrm{NF}-\mathrm{kB})(4)$. Furthermore, in CLL B-cells, curcumin has been shown to induce apoptosis in a dose-dependent manner by inhibiting constitutively active pro-survival pathways, including signal transducer and activator of transcription 3 (STAT3), and protein kinase B (AKT) (involving the key proteins phosphatidylinositol 3-kinase, AKT and NF-kB) (5). Curcumin has also been reported to play an immunomodulatory role in CLL in treatment of patients with CLL with Meriva ${ }^{\circledR}$, a nanocurcumin formulation of curcumin, resulted in an increase of CD4, CD8 and natural killer (NK) cells (6). In the multiple myeloma cell line NCI-H929, curcumin 
enhanced the cytotoxic and chemosensitizing effects of lenalidomide (7), while in U266 and RPMI-8226 cells, curcumin synergistically interacted with bortezomib to induce apoptosis (8). Curcumin has also been particularly of interest in the treatment of multiple myeloma because, unlike chemotherapy, it is toxic to cancer stem cells (9). Curcumin has been shown to work as an immunomodulator (10), and an inhibitor of histone deacetylase (11) and proteasome (12), actions proven to be effective in the treatment of patients with multiple myeloma. Curcumin blocks the actions of indoleamine 2,3-dioxygenase, an important checkpoint molecule which cancer cells secrete in order to cause suppression of the patient's immune system (13-15). A role for curcumin as maintenance therapy in the treatment of cancer has been proposed based on its inhibition of sphingosine kinase (16); sphingosine kinase inhibitors have been shown to possess synergistic anti-myeloma effects in myeloma cells (17). Sphigosine kinase is responsible for the production in the cell membrane of sphigosine 1-phosphate, which promotes cell proliferation and survival as well as angiogenesis $(16,17)$. Thus, curcumin has both cell membrane and intracellular (nuclear) targets that may mediate its anticancer effects.

Fluorescence polarization studies with curcumin have demonstrated its ability to be distributed within the cell membrane and nucleus, thus targeting both cellular sites of action. Following incubation of curcumin with normal mouse spleen and fibroblast cells, or with murine T-cell lymphoma and breast cancer cell lines, curcumin was initially located along the cell membrane, and then, at later times, in the nucleus $(18,19)$. Furthermore, curcumin was concentrated to a greater extent in cancer cell lines (18, 19), and when loaded into a liposome vehicle, more curcumin was distributed into cells compared to the use of human serum albumin or aqueous dimethyl sulfoxide as vehicles (19).

Upon incubation of Lipocurc ${ }^{\mathrm{TM}}$ with cryopreserved peripheral blood mononuclear cells (PBMCs) from healthy individuals and patients with CLL, PBMCs from patients had higher levels of curcumin (20). This is consistent with previous reports showing higher levels of curcumin in cancerous, compared to non-cancerous cells $(18,19)$.

In this study, we investigated the disposition of curcumin in B-lymphocytes from healthy individuals and in the myeloma cell lines RPMI-8266 and NCI-H929. Cell levels of curcumin were measured and its metabolism was monitored by measuring levels of the major stable metabolite tetrahydrocurcumin (THC) $(21,22)$ (Figure 1) in cells and assay medium. The data from these studies were then compared to previously published data for red blood cells (RBCs), peripheral blood mononuclear cells (PBMCs) from healthy individuals and PBMCs from patients with CLL (CLL cells).

\section{Curcumin}<smiles>COc1cc(/C=C/C(=O)CC(=O)/C=C/c2ccc(O)c(OC)c2)ccc1O</smiles>

THC<smiles>COc1cc(CCC(=O)CC(=O)CCc2ccc(O)c(OC)c2)ccc1O</smiles>

Figure 1. Chemical structures of curcumin and tetrahydrocurcumin (THC).

\section{Materials and Methods}

Lipocurc $^{\mathrm{TM}}$ (Polymun Scientific (Klosterneuburg, Austria). Lipocurc $^{\mathrm{TM}}$ contained $6.0 \mathrm{mg} / \mathrm{ml}$ curcumin, $72 \mathrm{mg} / \mathrm{ml}$ 14:0-1,2dimyristoyl-sn-glycero-3-phosphocholine and $8.0 \mathrm{mg} / \mathrm{ml} \mathrm{14:0-1,2-}$ dimyristoyl-sn-glycero-3-phosphorylglycerol. The average liposome size and distribution were a $\mathrm{Z}$-average of $117 \mathrm{~nm}$ and a zeta potential of $-36 \mathrm{mV}$ at $\mathrm{pH}$ 5.0. Upon receipt, Lipocurc ${ }^{\mathrm{TM}}$ was stored frozen at -10 to $-25^{\circ} \mathrm{C}$ and protected from light. Curcumin, THC, curcumin-d6 and THC-d6 were obtained from Toronto Research Chemicals (Toronto, ON, Canada).

Cryopreserved B-lymphocytes from healthy individuals (normal B-lymphocytes) were obtained from BioreclamationIVT (Westbury, NY, USA). They were a pool of B-cells isolated via positive selection with CD19 from three healthy individuals, a Black male aged 43 years and two Hispanic males aged 22 and 26 years old. For isolation of B-lymphocytes, blood samples were treated with sodium heparin. Cryopreservation was carried out using Cryostar CS10 from Biolife (Bothell, WA, USA). The preparation of B-lymphocytes was negative for human immunodeficiency virus, hepatitis $\mathrm{C}$ virus, and reactivity to hepatitis B DNA, West Nile virus RNA, anti-Zika virus RNA and sexually transmitted diseases. Upon receipt of the B-lymphocytes on dry ice, they were transferred and stored in liquid nitrogen. The human cryopreserved multiple myeloma cell lines RPMI-8226 and NCI-H929 were obtained from the American Type Culture Collection (Manassas, VA, USA) and distributed by Cedar Lane (Burlington, ON, Canada). Upon receipt of the myeloma cell lines on dry ice were transferred and stored in liquid nitrogen. Both myeloma cell lines were negative for human immunodeficiency virus, hepatitis B virus, human papilloma virus, Epstein-Barr virus and cytomegalovirus. All other reagents were obtained from standard commercial sources and were of reagent grade quality or higher.

Preparation of cells for distribution studies. The cells were prepared for use as follows. Normal B-lymphocytes, RPMI-8226 and NCIH929 cryopreserved cells were rapidly partially thawed by placing 
the cryotubes containing the cells in a water-bath at $37^{\circ} \mathrm{C}$ for $\sim 1-2$ min and then resuspending in a total volume of $15 \mathrm{ml}$ of ice-cold Krebs Henseleit incubation medium (KHIM) prepared as described previously (16). The cell suspensions were centrifuged at $2750 \times g$ for $20 \mathrm{~min}$ and the supernatant discarded. The pellets were gently resuspended in a minimum volume of ice-cold KHIM at total cell suspension density determined by counting cells on a hemocytometer of $35.7 \times 10^{6} \mathrm{cell} / \mathrm{s} / \mathrm{ml}$ for B-lymphocytes, $13.5 \times 10^{6}$ cells/ml for RPMI-8226 and $9.6 \times 10^{6}$ cells $/ \mathrm{ml}$ for NCI-H929. The cell suspensions were maintained at $4-8^{\circ} \mathrm{C}$ and supplemented with $\mathrm{O}_{2}$ prior to use within $2 \mathrm{~h}$ following preparation. The total cell count of the suspensions was determined using a hemocytometer.

Cell distribution studies. The preparation of incubation medium supplemented with human plasma proteins, preparation of stock solutions for curcumin from Lipocurc ${ }^{\mathrm{TM}}$ and the method used for studying the cell distribution of curcumin were described previously (16). The study on the distribution of curcumin was conducted using a $1.5 \mathrm{ml}$ conical microfuge using six replicates with a targeted incubation concentration of curcumin of $2 \pm 0.3 \mu \mathrm{M}(627-849 \mathrm{ng} / \mathrm{ml})$. Representative samples of cell pellets following incubation were taken and the average weight of the cell pellet was determined by pre-weighing the tubes and subtracting that weight from the weight of the tubes containing the cell pellet. The number of cells per gram wet weight of cell pellet was determined and used to calculate the cell level of curcumin and THC, then expressed per $10^{6}$ cells. For $\mathrm{RBC}$ cells, the cell number was determined from literature values for red blood density in whole blood as described previously (22). For published studies with PBMCs and CLL cells (20), the average number of cells per gram weight of pellet was determined over several cell preparations and used to calculate the cell levels of curcumin and THC expressed per $10^{6}$ cells.

Sample analysis. The levels of curcumin and THC were measured in cell extracts and incubation medium by liquid chromatograph tandem mass spectrometry using previously published methods $(20$, 22). The levels of curcumin and THC in the cells were expressed either as $\mathrm{ng} / \mathrm{g}$ w.w. cell pellet or $\mathrm{pg} / 10^{6}$ total cells counted. In addition, the total curcumin in the cell pellet and the total amount of THC in both cells and medium was calculated (pg). The sum of the amounts of curcumin and THC was determined and expressed as total curcuminoids (TC) (pg). Cell partition data for RBC, PBMCs and CLL cell levels of curcumin and THC were obtained from previous studies $(20,22)$.

Data analysis and statistics. Data are presented as the mean \pm standard error (SE) of the mean. All statistical tests were performed using SigmaStat (v 3.5; Systat Software Inc., San Jose, CA, USA). Twogroup comparisons were performed using Student's t-test. Multiplegroup comparisons were performed using a one-way analysis of variance (ANOVA) with either Student Newman Keul's or Dunn's post-hoc analysis. Differences were deemed statistically significant when they attained the $p<0.05$ level of significance.

\section{Results}

Cell viability was determined using the trypan blue method and found to be $77 \%$ for B-lymphocytes and 52\% for RPMI8226 and $28 \%$ for NCI-H929 myeloma cell lines. The average reported viability of PBMCs from healthy individuals and patients with CLL was 74\% (20). The low viability for the NCI-H929 cells was consistent with the lower expected viability of these cells upon thawing according to the distributor. However, the staining of NCI-H929 cells with trypan blue was not that intense and therefore, as described in the literature, cells with increased permeability may allow trypan blue to permeate them but at the same time remain metabolically active and viable (23). It is also important to note that during the cryopreservation process, cells exposed to DMSO undergo a change in membrane permeability, resulting in the potential for inadvertently taking up trypan blue, giving a false indication of low viability. Thus, NCIH929 cells may have been viable and metabolically active but somewhat more permeable to trypan blue. Therefore, it was decided to express the data for cell levels of curcumin and THC based on total cell counts rather than viable cell counts for all cell lines. In the microscope field, normal PBMCs and those from patients with CLL, and B-lymphocytes were of uniform size and rounded. In contrast, both RPMI-8226 and NCI-H929 cells were larger and less well rounded. The weight of the cell pellet was $16.5,12.0$ and $8.3 \mathrm{mg}$ for Blymphocytes and RPMI-8266 and NCI-H929 cells, respectively. Final cell counts per assay were $3.6 \times 10^{6}$, $1.4 \times 10^{6}$ and $1.0 \times 10^{6}$ for B-lymphocytes and RPMI-8266 and NCI-H929 cells, respectively.

The amounts of curcumin and THC (levels above the limit of detection) in B-lymphocytes, RPMI-8166 and NCI-H929 cell pellets and medium collected from cells incubated with curcumin at $37^{\circ} \mathrm{C}$ and the cell partition coefficients are presented in Table I. On a wet-weight basis, cell pellet levels of curcumin in RPMI-8266 and NCI-H929 cells were 3.5and 1.8-fold, 14.6- and 6.4-fold and 11.5- and 5.0-fold higher compared to B-lymphocytes, normal PBMCs and RBCs, respectively (Figure 2). When expressed based on cell number, the levels were 4.7- and 4.2-fold, 24- and 22-fold and 749- and 670-fold higher compared to B-lymphocytes, normal PBMCs and RBCs, respectively (Figure 2). The corresponding cell partition coefficients for RPMI-8266 and NCI-H929 cells were also higher compared to Blymphocytes. Data for PBMCs and CLL cells are presented in Table II. Compared to B-lymphocytes, the levels of curcumin in PBMCs were considerably lower. This was also true for a comparison of the cancerous cells, where the levels of curcumin in CLL cells were considerably lower than in the myeloma cell lines RPMI-8226 and NCI-H929.

Table III presents the cell and medium levels of THC for normal PBMCs and CLL cells. Cell and medium levels of THC for B-lymphocytes, RPMI-8226 and NCI-H929 cells were negligible. For PBMCs, the level of THC measured in the cells and medium was higher than that for B-lymphocytes. For CLL cells, the cell level of THC was comparable to that for PBMCs. However, for CLL cells, the medium level of THC was much lower compared to that for PBMCs. 

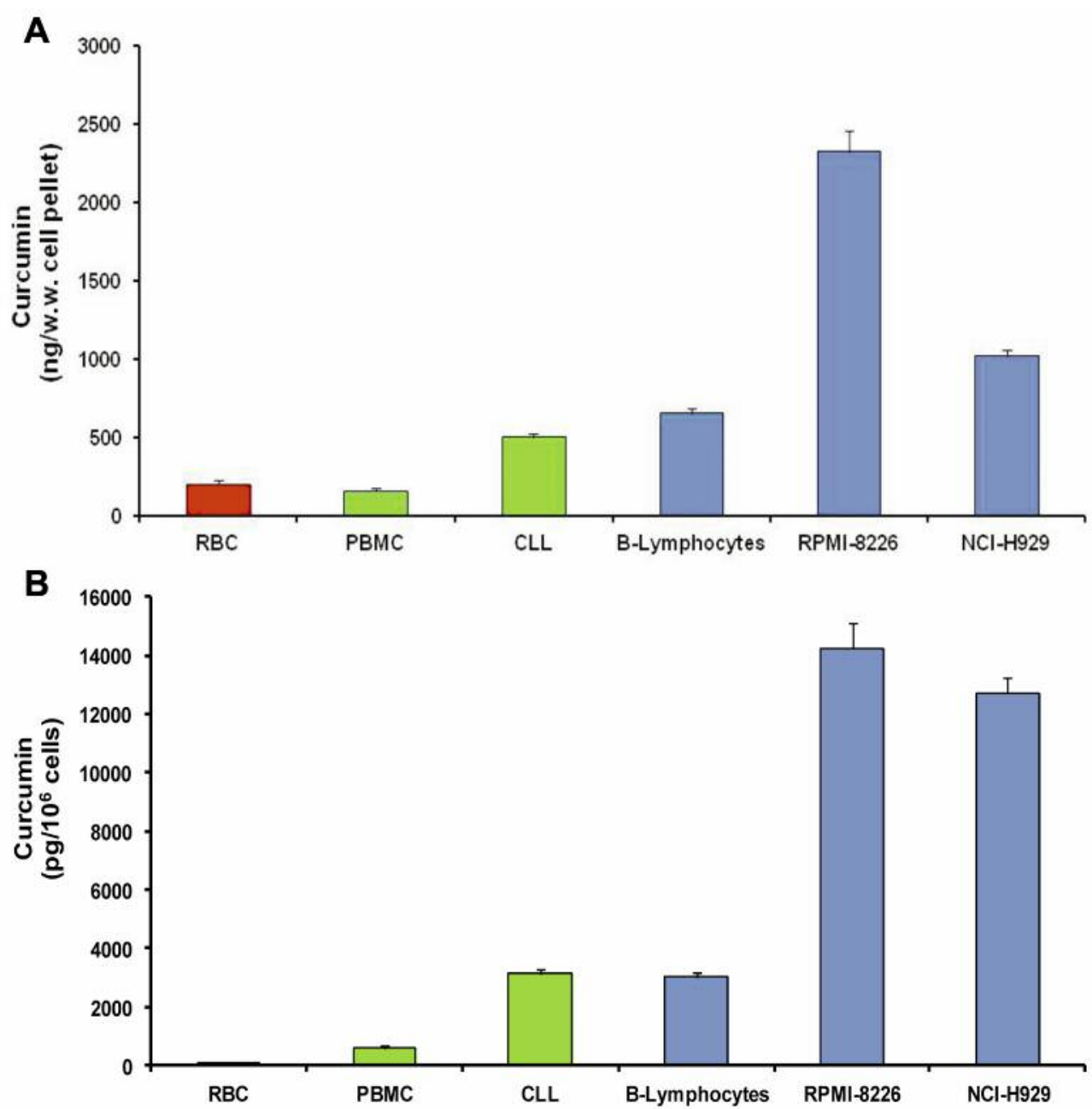

Figure 2. Comparative cell levels of curcumin in different human blood cell types, including red blood cells (RBCs), peripheral blood mononuclear cells (PBMCs) from healthy individuals, and PBMCs from patients with chronic lymphocytic leukemia (CLL cells). The data for RBCs were taken from previously published data (22). In panel $B$, for RBC the mean curcumin level was $19 \pm 5 \mathrm{pg} / 10^{6}$ cells. The data are presented as the mean $\pm S E$ of the determinations shown in Tables I and II.

Since THC is produced as a consequence of metabolism of curcumin within cells, it was of interest to calculate the total amount of THC produced in the assay (present in the cells and incubation medium) and compare it to the total amount of curcumin in the cell following incubation for all cell types. Total THC to curcumin ratios were highest in PBMCs, followed by CLL cells and lowest in B-lymphocytes and the myeloma cell lines. The results are presented in Table IV. TC levels were quite similar between PBMCs, CLL cells and B-lymphocytes, with a higher portion of the curcuminoids represented by curcumin in CLL cells compared to PBMCs. The myeloma cell lines contained the highest levels of $\mathrm{TC}$, which were almost all entirely represented by curcumin, and ranged from 4.2- to 4.7-fold greater per $10^{6}$ cells than the levels of TC in PBMCs, CLL cells and B-lymphocytes.

\section{Discussion}

From the data presented in this report, it is clear that curcumin is distributed to a strikingly higher degree in the myeloma cell lines RPMI-8226 and NCI-H929 compared to B-lymphocytes, with fold increases per $10^{6}$ cells ranging from 4.2- to 4.7-fold. Furthermore, fold increases ranging from 22- to 24-fold and 670- to 749-fold were observed compared to PBMCs and RBCs, respectively. As in a past study (20), the distribution of curcumin in these cells was measured in a medium richly supplemented with human plasma proteins, adding to their physiological relevance. These findings are consistent with the growing body of evidence demonstrating that upon exposure to curcumin, cell levels of curcumin are higher in cancerous cells than in normal cells (18-20). It has been speculated that the higher levels of curcumin in cancer cells may be attributed 
Table I. Cell levels of curcumin and partition coefficients (Kp) for B-cells and RPMI-8266 and NCI-H929 myeloma cell lines following incubation with curcumin. Values are presented as the mean \pm SE of 6.

\begin{tabular}{lcccc}
\hline Cell type & \multicolumn{4}{c}{ Curcumin } \\
\cline { 2 - 3 } & Cell pellet (ng/g w.w.) & Cells (pg/106 cells) & Medium (ng/ml) & Kp \\
\hline B-Lymphocytes & $655 \pm 29$ & $3,026 \pm 135$ & $796 \pm 35$ & $0.83 \pm 0.07$ \\
RPMI-8266 & $2,325 \pm 135^{*}$ & $14,225 \pm 847^{*}$ & $837 \pm 66$ & $2.87 \pm 0.295^{*}$ \\
NCI-H929 & $1,018 \pm 40^{*}$ & $12,723 \pm 500^{*}$ & $768 \pm 54$ & $1.35 \pm 0.097^{*}$ \\
\hline
\end{tabular}

w.w.: Wet weight of cell pellet. \#Measured following incubation. Kp: Ratio of the cell level to the mean concentration in medium for 15 -minute incubation, assuming that $1 \mathrm{~g}$ of cell pellet has a volume of $1 \mathrm{ml}$. *Significantly different from B-lymphocytes at $p<0.05$ by one-way ANOVA.

Table II. Cell levels of curcumin and partition coefficients (Kp) for peripheral blood mononuclear cells (PBMCs) and PBMCs from patients with chronic lymphocytic leukemia (CLL cells) following incubation with curcumin. Values are presented as the mean $\pm S E$ of $n=7$ for PBMCs and $n=15$ for CLL.

\begin{tabular}{lcccc}
\hline & \multicolumn{4}{c}{ Curcumin } \\
\cline { 2 - 4 } Cell type & Cell pellet (ng/g w.w.) & Cells (pg/106 cells) & Medium (ng/ml) & Kp \\
\hline PBMCs & $159 \pm 17$ & $587 \pm 86$ & $896 \pm 50$ & $0.19 \pm 0.022$ \\
CLL & $501 \pm 27^{*}$ & $3,122 \pm 166^{*}$ & $820 \pm 49$ & $0.65 \pm 0.053^{*}$ \\
\hline
\end{tabular}

w.w.: Wet weight of cell pellet. \#Measured following incubation. Kp: Ratio of the cell level to the mean concentration in medium for 15 -minute incubation, assuming that $1 \mathrm{~g}$ of cell pellet has a volume of $1 \mathrm{ml}$. *Significantly different from PBMCs at $p<0.05$ by the Student's $t$-test.

Table III. Cell levels of tetrahydrocurcumin (THC) and ratio of THC/curcumin for peripheral blood mononuclear cells (PBMCs) and PBMCs from patients with chronic lymphocytic leukemia (CLL cells) following incubation with curcumin. Values are presented as the mean $\pm S E$ of $n=7$ for PBMCs and $n=15$ for $C L L$.

\begin{tabular}{|c|c|c|c|c|}
\hline \multirow[b]{2}{*}{ Cell type } & \multicolumn{3}{|c|}{ THC } & \multirow[b]{2}{*}{ Ratio THC/curcumin } \\
\hline & Cell pellet (ng/g w.w.) & Cells (pg/106 cells) & Medium $(\mathrm{ng} / \mathrm{ml})^{\#}$ & \\
\hline PBMCs & $31.7 \pm 3.7$ & $113 \pm 13$ & $22.4 \pm 4.5$ & $0.21 \pm 0.02$ \\
\hline CLL & $29.4 \pm 2.6$ & $184 \pm 16^{*}$ & $2.5 \pm 0.8^{*}$ & $0.06 \pm 0.01 *$ \\
\hline
\end{tabular}

w.w.: Wet weight of cell pellet. "Measured following incubation. ${ }^{\ddagger}$ Ratio based on ng/g w.w. *Significantly different from PBMCs at $p<0.05$ by the Student's $t$-test.

Table IV. Levels of curcumin, total tetrahydrocurcumin (THC) and total curcuminoid (TC) levels in normal cells, cancerous cell lines, peripheral blood mononuclear cells (PBMCs) and PBMCs from patients with chronic lymphocytic leukemia (CLL cells). Values are presented as the mean \pm SE of $n=6$ for B-cells, RPMI-8266 and NCI-H929 cells, $n=7$ for PBMCs and $n=15$ for CLL.

\begin{tabular}{|c|c|c|c|c|c|c|}
\hline \multirow[t]{2}{*}{ Cell type } & \multirow{2}{*}{$\begin{array}{l}\text { Curcumin in } \\
\text { cells (pg) }\end{array}$} & \multirow{2}{*}{$\begin{array}{l}\text { Total THC } \\
\quad(\mathrm{pg})^{\#}\end{array}$} & \multirow{2}{*}{$\begin{array}{l}\text { Ratio of THC } \\
\text { to curcumin }\end{array}$} & \multicolumn{3}{|c|}{$\mathrm{TC}$} \\
\hline & & & & (pg) & (ng/g w.w.) & (pg/10 6 cells) \\
\hline PBMCs & $2637 \pm 369$ & $11,346 \pm 2546$ & 4.30 & $13,983 \pm 2269$ & $858 \pm 133$ & $3,063 \pm 474$ \\
\hline B-Lymphocytes & $10,804 \pm 483$ & $107 \pm 67$ & 0.010 & $10,911 \pm 438$ & $661 \pm 27$ & $3,056 \pm 123$ \\
\hline CLL & $9,509 \pm 505$ & $2,083 \pm 484$ & 0.22 & $11,593 \pm 558$ & $620 \pm 33$ & $3,873 \pm 209$ \\
\hline RPMI-8266 & $19,204 \pm 1117$ & $55 \pm 55$ & 0.003 & $19,259 \pm 1109$ & $2,332 \pm 134 *$ & $14,266 \pm 821 * *$ \\
\hline NCI-H929 & $12,214 \pm 480$ & $0 \pm 0$ & 0.00 & $12,214 \pm 480$ & $1,018 \pm 40$ & $12,723 \pm 400 * *$ \\
\hline
\end{tabular}

TC: The sum of cell levels of curcumin and THC, and THC in the cell medium following incubation. w.w.: Wet weight of cell pellet. \#Measured following incubation. Significantly different from *B-lymphocytes and CLL, and ** from PBMCs, CLL and B-lymphocytes, at $p<0.05$ by one-way ANOVA. 
to their greater degree of membrane fluidity $(20,24-27)$. Of greater importance is that the increased levels of curcumin in cancerous cells may be associated with a greater cytotoxicity of curcumin to cancer cells compared to normal cells. Consistent with this premise, B-lymphocytes from patients with CLL were found to have a 4-fold greater sensitivity to the apoptotic effects of curcumin compared to B-lymphocytes from a healthy individual (4). This is in good agreement with the 3.5-fold higher level of curcumin in the cell pellet (wet weight) observed for RPMI-8226 cells and with the 4.2- and 4.7-fold increase in curcumin levels in NCIH929 and RPMI-8226 cells when expressed per $10^{6}$ cells, respectively. Furthermore, the selectively very high distribution of curcumin into myeloma cells compared to B-lymphocytes, PBMCs and RBCs, makes them an excellent target for the anticancer effects of curcumin.

Another interesting observation made from this study was that the level of curcumin observed in B-lymphocytes was higher than in PBMCs, and that for RPMI-8226 and NCI-H929 were higher than for CLL cells. One reason for this discrepancy may be that PBMCs are a heterogenous population and that the uptake of curcumin into non-B-lymphocytes may indeed be lower both in healthy individuals and patients with cancer. Another possible explanation may be the metabolism of curcumin by cells, in particular, by curcumin reductase leading to THC. Several lines of experimental evidence support this premise. Firstly, PBMCs produced considerably more THC compared to B-lymphocytes, suggesting that the metabolism of curcumin in B-lymphocytes was less than it is in PBMCs, resulting in a higher cell level of curcumin. Secondly, higher curcumin but lower THC levels were observed in CLL cells compared to PBMCs, suggesting that the higher level of curcumin in CLL cells may in part be due to its lower metabolism. Thirdly, in the myeloma cell lines, curcumin levels were considerably higher compared to those in CLL cells, however, there was considerably more metabolism of curcumin to THC by CLL cells compared to myeloma cell lines. Thus, the degree of metabolism of curcumin by curcumin reductase may have an important bearing on the cell level of curcumin in both normal and cancerous cell lines.

The importance of the metabolism of curcumin to THC was further assessed by comparing the TC of the different cell types. Of interest was the finding that for cells of similar size, namely, B-lymphocytes, PBMCs and CLL cells, TC levels were quite similar. For PBMCs, the TC were dominated by THC, while for B-lymphocytes and CLL cells, they were dominated by curcumin. Therefore, it would appear that the uptake of curcumin into these cells was similar, with the level of curcumin measured following incubation determined by the metabolism of curcumin to THC. The myeloma cell lines contained the highest TC levels, which were clearly dominated by curcumin and most evident when levels were expressed per $10^{6}$ cells. Curcumin was found to be the most active curcuminoid for suppression of NF-KB (28) and inflammatory pathways in Alzheimer's disease (29). With respect to the metabolites of curcumin, THC was observed to have, lesser, similar or greater pharmacological activities depending on the biological system investigated (30) and the conjugated metabolites of curcumin reportedly mediate their antitumor effects through conversion to curcumin (31). Thus, the propensity of cancer cells, in particular myeloma, cells to have strikingly higher levels of curcumin (either due to physical differences in the cell membrane or differences in the metabolism of curcumin compared to normal cells), may offer an advantage for the treatment of myeloma.

In summary, similarly to previous observations of increased cell levels of curcumin in PBMCs (20), strikingly higher levels of curcumin were found in the myeloma cell lines NCI-H929 and RPMI-8266 compared to B-lymphocytes. Metabolism of curcumin to THC may be relevant to the disposition of curcumin in both normal and cancer cells. The higher levels of curcumin observed in cancer cells, particularly the strikingly high levels in myeloma cells, offers a treatment advantage that may be realized by the combination of curcumin with current anticancer drugs for both primary and maintenance therapy of CLL and myeloma (1-3). Intravenous infusion of Lipocurc ${ }^{\mathrm{TM}}$ may be a viable treatment route since a recent clinical trial in patients with cancer indicated that mean maximal plasma concentrations of curcumin ranging from 1,428 to $1,641 \mathrm{ng} / \mathrm{ml}$ over $6-8 \mathrm{~h}$ of infusion could be achieved and were well tolerated (32).

\section{Conflicts of Interest}

The Authors have no disclosure of conflict of interest in regard to this study.

\section{Authors' Contributions}

G.T.B. conducted the in vitro cell distribution experiments and wrote the article; A.L. provided guidance in the design of the experiments and interpretation of the data; R.B. and A.T. provided bioanalytical support; R.G. provided patient blood cell samples; B.V. and M.M. were involved in the production of Lipocurc ${ }^{\mathrm{TM}}$; P.S. was involved in the writing of the article and provided financial support to conduct these studies. All Authors critically reviewed the article.

\section{References}

1 Shanbhag VKL: Curcumin in chronic lymphocytic leukemia - A review. Asian Pac J Trop Biomed 7: 505-512, 2017. DOI: 10.1016/j.apjtb.2017.05.003.

2 Bange E, Timlin C, Kabel C, Svoboda J, Roeker L and Mato AR: Evidence for and against green tea and turmeric in the management of chronic lymphocytic leukemia. Clin Lymph Myeloma Leuk 10: e421-e426, 2018. PMID: 30007569. DOI: 10.1016/j.clml.2018.06.021. 
3 O'Brien S and Kay NE: Maintenance therapy for B-chronic lymphocytic leukemia. Clin Adv Hematol Oncol 9: 22-31, 2011. PMID: 21326143.

4 Everett PC, Meyers JA, Makkinje A, Rabbi M and Lerner A: Preclinical assessment of curcumin as a potential therapy for BCLL. Amer J Hematol 82: 23-30, 2007. PMID: 16947318. DOI: 10.1002/ajh.20757.

5 Ghosh AK, Kay NE, Secreto CR and Shanafelt TD: Curcumin inhibits prosurvival pathways in chronic lymphocytic leukemia $\mathrm{B}$ cells and may overcome their stromal protection in combination with EGCG Clin Cancer Res 15: 1250-1258, 2009. PMID: 19228728. DOI: 10.1158/1078-0432.CCR-08-1511.

6 Golombick T, Diamond TH, Manoharan A and Ramakrishna R: The effect of curcumin (as Meriva) on absolute lymphocyte count (ALC) NK cells and T-cell populations in patients with state 0/1 chronic lymphocytic leukemia. Cancer Ther 6: 566-571, 2015. DOI: $10.4236 /$ jct.2015.67061.

7 Wong R. Golombick T, Diamond TH, Manoharan A and Ramakrishna R: Curcumin enhances the cytotoxic and chemosensitizing effects of lenalidomide in human multiple myeloma cells. J Hematol Malign 3: 1-7, 2013. DOI: 10.5430/ jhm.v3n2p1.

8 Park J, Ayyappan V, Bae E-K, Lee C, Kim B-S, Kim BK, Lee Y-Y, Ahn K-S and Yoon S-S: Curcumin in combination with bortezomib synergistically induced apoptosis in human multiple myeloma U266 cells. Mol Oncol 2: 317-326, 2008. PMID: 19383353. DOI: 10.1016/j.molonc.2008.09.006.

9 Sordillo PP and Helson L: Curcumin and cancer stem cells: curcumin has asymmetrical effects on cancer and normal stem cells. Anticancer Res 35: 599-614, 2015. PMID: 25667437.

10 Srivastava RM, Singh S, Dubey SK, Misra K and Khar A: Immunomodulatory and therapeutic activity of curcumin. Int Immunopharmacol 11: 331-341, 2011. PMID: 20828642. DOI: 10.1016/j.intimp.2010.08.014.

11 Soflaei SS, Momtazi-Borojeni AA, Majeed M, Derosa G, Maffioli P and Sahebkar A: Curcumin: a natural pan-HDAC inhibitor in cancer. Curr Pharm Design 24: 123-129, 2018. PMID: 29141538. DOI: 10.2174/1381612823666171114165051.

12 Hasima $\mathrm{N}$ and Aggarwal B: Targeting proteasomal pathways by dietary curcumin for cancer prevention and treatment. Curr Med Chem 14: 1583-1594, 2014. PMID: 23834173. DOI: 10.2174/ 09298673113206660135.

13 Jeong YI, Kim SW, Jung ID, Lee JS, Chang JH, Lee CM, Chun SH, Yoon MS, Kim GT, Ryu SW and Kim JS: Curcumin suppresses the induction of indoleamine 2,3-dioxygenase by blocking the Janus-activated kinase-protein kinase C-STAT1 signaling pathway in interferon- $\gamma$-stimulated murine dendritic cells. J Biol Chem 284: 3700-3708, 2009. PMID: 19075017. DOI: $10.1074 /$ jbc.M807328200.

14 Sordillo P, Sordillo, LA and Helson L: The kynurenine pathway: A primary resistance mechanism in patients with glioblastoma. Anticancer Res 37: 2159- 2171, 2017. PMID: 28476779. DOI: 10.21873/anticanres.11551.

15 Varshini.C, Vinitha P, Priyanka R, Ramaraj K and Ronaldo AA: In silico analysis of curcumin and its analogues as potential inhibitors of indoleamine 2,3-dioxygenase. J Pharm Res 4: 335-339, 2015. PMID: 30126306. DOI: 10.1080/147563 66. 2018.1488695.

16 Sordillo LA, Sordillo PP and Helson L: Sphingosine kinase inhibitors as maintenance therapy of glioblastoma after ceramideinduced response. Anticancer Res 36: 2085-2096, 2016. PMID: 27127108 .
17 Sundaramoorthy $\mathrm{P}$, Gasparetto $\mathrm{C}$ and Khang Y: The combination of a sphingosine kinase 2 inhibitor (ABC294640) and a BCL inhibitor (ABT-199) displays synergistic antimyeloma effects in myeloma cells without a $\mathrm{t}(11 ; 14)$ translocation. Cancer Med 7: 3257-3268, 2018. PMID: 29761903. DOI: 10.1002/cam4.1543.

18 Kunwar A, Barik A, Pandey R and Priyadarsini KI: Transport of liposomal and albumin loaded curcumin to living cells: An absorption and fluorescence spectroscopic study. Biochim Biophys Acta 1780: 673-679, 2008. PMID: 16904830. DOI: 10.1016/j.bbagen.2006.06.012.

19 Kunwar A, Barik A, Mishra B, Rathinasamy K, Pandey R and Priyadarsini KI: Qualitative cellular uptake, localization and cytotoxicity of curcumin in normal and tumor cells. Biochim Biophys Acta 1780: 673-679, 2008. PMID: 18178166. DOI: 10.1016/j.bbagen.2007.11.016.

20 Bolger GT, Licollari A, Tan A, Greil R, Pleyer L, Vcelar B, Majeed M and Sordillo P: Distribution of curcumin and THC in peripheral blood mononuclear cells isolated from healthy individuals and patients with chronic lymphocytic leukemia. Anticancer Res 38: 121-130, 2018. PMID: 29277764. DOI: 10.21873/anticanres.12199.

21 Ireson C, Orr S, Jones DLL, Verschoyle R, Lim CK, Luo JL, Howells L, Plummer S, Jukes R, Williams M, Steward WP and Gescher A: Characterization of metabolites of the chemopreventive agent curcumin in human and rat hepatocytes and in the rat in vivo, and evaluation of their ability to inhibit phorbol ester-induced prostaglandin $\mathrm{E}_{2}$ production. Cancer Res 61: 1058-1064, 2001. PMID: 11221833.

22 Bolger GT, Licollari A, Tan A, Greil R, Vcelar B, Majeed M and Helson L: Distribution and metabolism of Lipocurc ${ }^{\mathrm{TM}}$ (Liposomal curcumin) in dog and human blood cells: Species selectivity and pharmacokinetic relevance. Anticancer Res 37: 3483-3492, 2017. PMID: 28668837. DOI: 10.21873/ anticanres.11716.

23 Tran S-L, Puhar A, Ngo-Camus M and Ramarao N: Trypan blue dye enters viable cells incubated with the pore-forming toxin HIyII of Bacillus cereus. PLOS One 6: 1-5: e22876, 2011. PMID: 21909398. DOI: 10.1371/journal.pone.0022876.

24 Inbar M, Ben-Bassat H, Fibach E and Sachs L: Mobility of carbohydrate-containing structures on the surface membrane and the normal differentiation of myeloid leukemic cells to macrophages and granulocytes. Proc Natl Acad Sci 70: 25772581, 1973. PMID: 4517672.

25 Ben-Bassat H, Polliak A, Rosenbaum SM, Naparstek E, Shouval $\mathrm{D}$ and Inbar M: Fluidity of membrane lipids and lateral mobility of concanavalin A receptors in the cell surface of normal lymphocytes and lymphocytes from patients with malignant lymphomas and leukemias. Cancer Res 37: 1307-1312, 1977. PMID: 856460.

26 Yanovich S, Harris K, Sallan SE, Schlossman SF and Inbar M: Dynamic parameters of membrane lipids in normal and leukemic human lymphocytes isolated from peripheral blood and bone marrow. Cancer Res 38: 4654-4661, 1978. PMID: 309792.

27 Andoh Y, Okazaki S and Ueoka R: Molecular dynamics study of lipid bilayers modeling the plasma membranes of normal murine thymocytes and leukemic GRSL cells. Biochim Biophys Acta 1828: 1259-1270, 2013. PMID: 23333323. DOI: 10.1016/j.bbamem. 2013.01.005. 
28 Sandur SK, Pandey MK, Sung B, Ahn KS, Murakami A, Sethi G, Limtrakul P, Badmaev V and Aggrawal BB: Curcumin, demethoxycurcumin, bisdemethoxycurcumin, tetrahydrocurcumin and turmerones differentially regulate anti-inflammatory and antiproliferative responses through a ROS-independent mechanism. Carcinogenesis 28: 1765-1773, 2007. PMID: 17522064. DOI: $10.1093 /$ carcin/bgm123.

29 Begum AN, Jones MR, Lim GP, Morihara t, Kim P, Heath DD, Rock CL, Pruitt MA, Yang F, Hudspeth B, Hu S, Faull KF, Teter B, Cole GM and Frautschy SA: Curcumin structure-function, bioavailability and efficacy in models of neuroinflammation and Alzheimer's disease. J Pharm Exp Ther 326: 196-298, 2008. PMID: 18417733. DOI:10.1124/jpet.108.137455.

30 Murugan P and Pari L: Influence of tetrahydrocurcumin on hepatic and renal functional markers and protein levels in experimental type 2 diabetic rats. Basic Clin Pharmacol Toxicol 101: 241-245, 2007. PMID: 17845505. DOI: 10.1111/j.17427843.2007.00109.x.
31 Ozawa H, Imaizumi A, Sumi Y, Hasimoto T, Kainai M, Makino Y, Tusda $\mathrm{T}$, Takahasi $\mathrm{N}$ and Kakeya H: Curcumin $\beta$-Dglucuronide plays an important role to keep high levels of freeform curcumin in the blood. Biol Pharm Bull 40: 1515-1524, 2017. PMID: 28867734. DOI: 10.1248/bpb.b17-00339.

32 Greil R, Greil-Ressler S, Weiss L, Schönlieb C, Magnes T, Radi B, Bolger GT, Vcelar B and Sordillo PP: A phase I dose-escalation study on the safety, tolerability and activity of liposomal curcumin (Lipocurc $^{\mathrm{TM}}$ ) in patients with locally advanced or metastatic cancer. Cancer Chemother Pharmacol 82: 695-706, 2018. PMID: 30074076. DOI: 10.1007/s00280-018-3654-0.

Received January 18, 2019

Revised February 4, 2019

Accepted February 6, 2019 